\title{
Low Haemoglobin Levels are Associated with Reduced Psychomotor and Language Abilities in Young Ugandan Children
}

\author{
Margaret Nampijja ${ }^{1,2 *}$, Agnes M Mutua ${ }^{3 *}$, Alison M Elliott ${ }^{2,4}$, John Muthii Muriuki $^{3}$, Amina \\ Abubakar ${ }^{3,5,6,7}$, Emily L Webb ${ }^{8}$ and Sarah H Atkinson ${ }^{3,9,10}$
}

1 Maternal and Child Wellbeing (MCW) Unit, African Population and Health Research Center, Nairobi 00100, Kenya; maggie.nampijja@ gmail.com (M.N.)

2 Medical Research Council / Uganda Virus Research Institute and London School of Hygiene and Tropical Medicine Uganda Research Unit, Entebbe, Uganda; Alison.Elliott@1shtm.ac.uk (A.M.E.)

3 Kenya Medical Research Institute (KEMRI) Centre for Geographic Medicine Research-Coast, KEMRI Wellcome Trust Research Programme, Kilifi 80108, Kenya

${ }^{4}$ Department of Clinical Research, London School of Hygiene and Tropical Medicine, London, UK, WC1E 7HT

5 Department of Public Health, School of Human and Health Sciences, Pwani University, Kilifi, Kenya

${ }^{6}$ Department of Psychiatry, University of Oxford, Oxford, UK, OX3 7JX

${ }^{7}$ Institute for Human Development, Aga Khan University, Nairobi, Kenya; AAbubakar@kemriwellcome.org (A.A.)

${ }^{8}$ MRC International Statistics and Epidemiology Group, Department of Infectious Disease Epidemiology, London School of Hygiene and Tropical Medicine, London, UK, WC1E 7HT; Emily.Webb@1shtm.ac.uk (E.L.W.)

9 Centre for Tropical Medicine and Global Health, Nuffield Department of Medicine, University of Oxford, Oxford, UK, OX3 7FZ

${ }^{10}$ Department of Paediatrics, University of Oxford, Oxford, UK, OX3 9DU

\section{*Joint first authors \\ Correspondence: Mutindiagnes@ gmail.com (A.M.M.); SAtkinson@kemri-wellcome.org (S.H.A.); Tel.:+254-709983677/76 (A.M.M., S.H.A.)}

\begin{abstract}
Children living in Sub-Saharan Africa are vulnerable to developmental delay, particularly in the critical first five years due to various adverse exposures including disease and nutritional deficiencies. Anaemia and iron deficiency (ID) are highly prevalent in pregnant mothers and young children and are implicated in abnormal brain development. However, available evidence on the association between anaemia, ID and neurodevelopment in Sub-Saharan Africa is limited. Using data from the Entebbe Mother and Baby Study prospective birth cohort, we examined the effect of maternal and child haemoglobin $(\mathrm{Hb})$ levels and child iron status on developmental scores in 933 and 530 pre-school Ugandan children respectively. Associations between $\mathrm{Hb}$ levels, iron status and developmental scores were assessed using regression analyses adjusting for potential confounders. Lower maternal and child $\mathrm{Hb}$ levels were associated with reduced psychomotor scores at 15 months, while only lower $\mathrm{Hb}$ levels in infancy were associated with reduced language scores. We found no evidence that anaemia or ID was associated with cognitive or motor scores at five years. This study emphasizes the importance of managing anaemia in pregnancy and infancy and highlights the need for further studies on the effects of anaemia and ID in children living in Sub-Saharan Africa.
\end{abstract}

Keywords: anaemia, iron, motor, cognitive, language, maternal, child, development, Africa 


\section{Introduction}

About 81 million pre-school children in low- and middle-income countries have delayed cognitive and socioemotional development and $43.8 \%$ of these children live in Sub-Saharan Africa [1]. African children are vulnerable to developmental delay due to exposure to various risk factors including inadequately stimulating home environments, infections, malnutrition and micronutrient deficiencies $[1,2]$. Iron deficiency (ID) accounts for over $40 \%$ of all anaemia cases and children living in Sub-Saharan Africa have the highest burden of ID and anaemia globally [3,4]. It is estimated that approximately $60 \%$ of pre-school children living in Africa are anaemic and 52\% are iron deficient $[3,5]$. Additionally, $38 \%$ of pregnant women are anaemic $(\mathrm{Hb}<11 \mathrm{~g} / \mathrm{dL})$ globally and of these women, $46.3 \%$ live in Africa $[6,7]$.

Animal and in vitro studies suggest that iron may influence neurobehavioural outcomes through its role in brain development. Studies report that iron is important for neurotransmitter synthesis and function, myelin formation, and DNA synthesis and repair in the brain [8-10]. In animal studies, ID is linked to impaired learning, memory function and behavioural changes which may be reversed by iron supplementation [11-13]. Despite the high prevalence of anaemia and ID in Sub-Saharan Africa, few studies have investigated its impact on early developmental outcomes and findings from these studies were mixed (Supplementary Table 1). There is also limited evidence on the longitudinal effects of anaemia and ID prenatally and in early childhood on neurobehavioural outcomes assessed at different timepoints in pre-school African children. Only two cohort studies have evaluated the relationship between $\mathrm{Hb}$, iron status and neurobehavioural outcomes in young African children. One multi-country study reported associations between child $\mathrm{Hb}$, iron status and motor and language development in children at 18 months but reported no associations between maternal $\mathrm{Hb}$, iron status and child development [14]. In one cohort, an inverted U-shaped association was reported between maternal $\mathrm{Hb}$ during pregnancy and motor development at one year but maternal iron status was not associated with child development $[15,16]$.

Using data from a large longitudinal, prospective birth cohort study, the Entebbe Mother and Baby Study (EMaBS), our study addressed three aims assessing: 1) the effect of $\mathrm{Hb}$ levels during pregnancy and early childhood on developmental scores at 15 months; and 2) at five years of age; and 3) the effect of ID and IDA at two years of age on developmental scores at five years of age.

\section{Materials and Methods}

\subsection{Study Design and Setting}

The Entebbe Mother and Baby Study (EMaBS) prospective birth cohort began as a double-blind placebocontrolled randomized controlled trial of the effects of anthelminthic treatment in pregnancy and childhood on immunological and disease outcomes in childhood (ISRCTN32849447), as described elsewhere [17]. Briefly, pregnant women were enrolled into the EMaBS during their first antenatal care clinic visit at Entebbe hospital and randomized to receive either albendazole or placebo and praziquantel or placebo in a $2 \times 2$ factorial design. Their children formed the EMaBS birth cohort that was followed up from birth with scheduled annual visits when anthropometric measurements and blood samples were taken. At age 15 months, children were randomized to receive either quarterly albendazole or placebo up to five years of age. Maternal health and sociodemographic data were collected at enrolment. Children were actively followed up and tested for malaria and other infections during quarterly visits to the study clinic. Maternal $\mathrm{Hb}$ levels were measured at enrolment during the second or third trimester of pregnancy while $\mathrm{Hb}$ levels were measured annually in children. Mothers with $\mathrm{Hb}$ levels $<8 \mathrm{~g} / \mathrm{dL}(\mathrm{n}=54)$ were treated with albendazole and excluded from the study at enrolment. Biomarkers of iron status were measured at two years of age while child developmental scores were assessed at 15 months and five years using locally adapted tools.

The aims of the current study were: 1) to assess the effect of maternal $\mathrm{Hb}$ levels and mild anaemia during pregnancy, and $\mathrm{Hb}$ levels and moderate anaemia in children at one year on developmental scores at 15 months; 2) to assess the effect of maternal and childhood $\mathrm{Hb}$ levels and any moderate anaemia event at or below five 
medRxiv preprint doi: https://doi.org/10.1101/2022.03.02.22271741; this version posted March 3, 2022. The copyright holder for this preprint (which was not certified by peer review) is the author/funder, who has granted medRxiv a license to display the preprint in perpetuity.

It is made available under a CC-BY 4.0 International license .

years of age on developmental scores at five years of age; and 3) to assess the effects of ID and IDA at two years of age on developmental scores at five years of age (Figure 1).

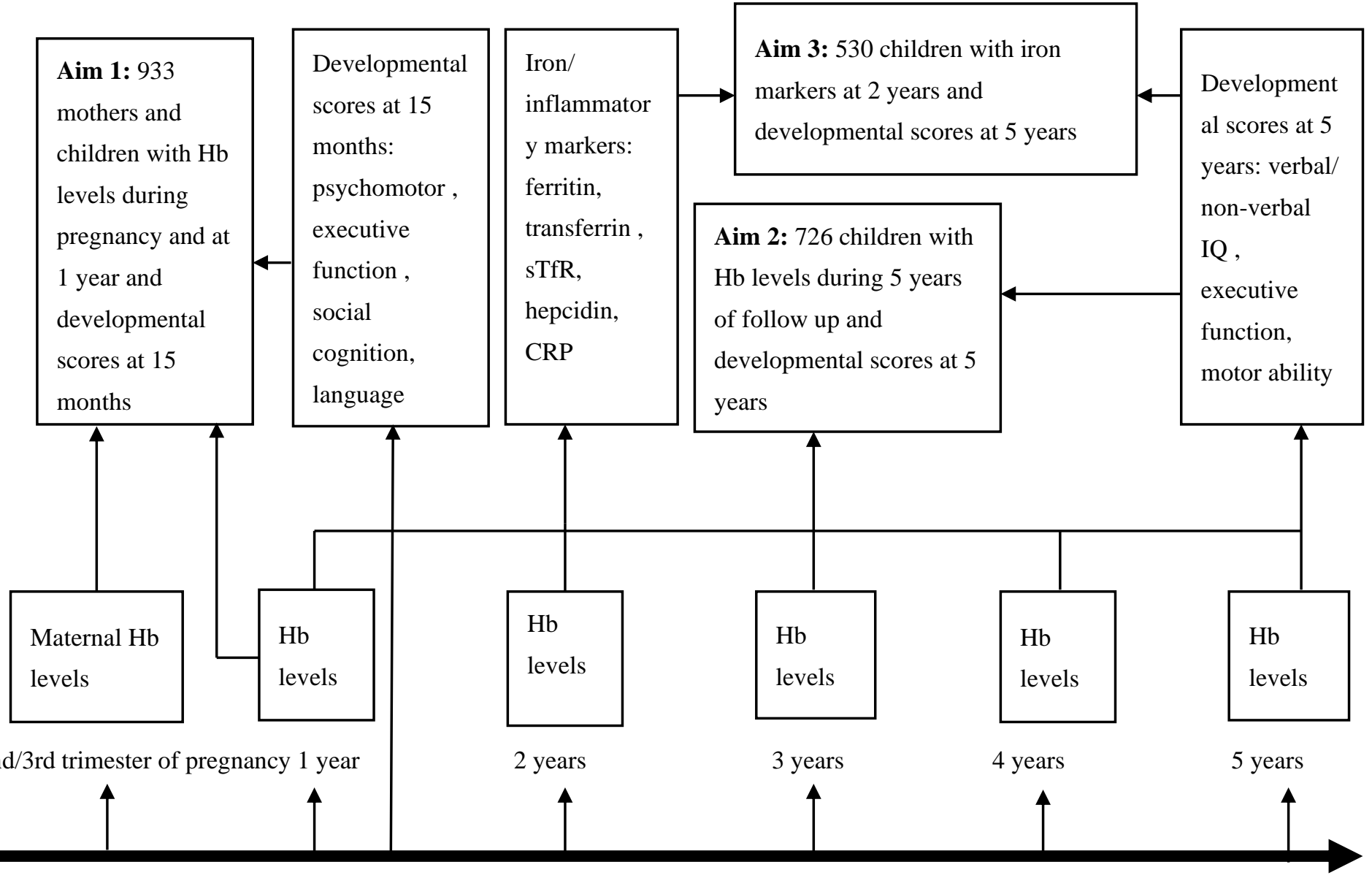

Figure 1: Study design. CRP, C-reactive protein; Hb, haemoglobin levels; sTfR, soluble transferrin receptor.

\subsection{Laboratory procedures and definitions}

$\mathrm{Hb}$ levels and mean corpuscular volume (MCV) in mothers and children were measured using the Coulter analyser (Beckman Coulter AC-T 5 diff CP; Beckman Coulter, Nyon, Switzerland). Measures of iron status included plasma ferritin (chemiluminescent microparticle immunoassay [CMI], Abbott Architect), soluble transferrin receptor (sTfR) (Human sTfR ELISA, BioVendor, CZ), transferrin (CMI, Abbott Architect), hepcidin (DRG hepcidin 25 [bioactive] High Sensitive enzyme-linked immunosorbent assay [ELISA] kit, DRG Diagnostics) and C-reactive protein (CRP) levels (MULTIGENT CRP Vario assay, Abbott Architect). Inflammation was defined as $\mathrm{CRP}>5 \mathrm{mg} / \mathrm{L}$ [18], while iron deficiency (ID) was defined using the WHO recommended definition as plasma ferritin $<12 \mu \mathrm{g} / \mathrm{L}$ in the absence of inflammation or $<30 \mu \mathrm{g} / \mathrm{L}$ in the presence of inflammation [19]. Mild anaemia was defined as $\mathrm{Hb}<11 \mathrm{~g} / \mathrm{dL}$, moderate anaemia as $\mathrm{Hb}<10 \mathrm{~g} / \mathrm{dL}$ and severe anaemia as $\mathrm{Hb}<7 \mathrm{~g} / \mathrm{dL}$ after adjusting for altitude $(1000 \mathrm{~m}$ above sea level) by subtracting $0.2 \mathrm{~g} / \mathrm{dL}$ from all $\mathrm{Hb}$ values [20]. Iron deficiency anaemia (IDA) was defined as the presence of both ID and mild anaemia. Microcytic anaemia was defined as $\mathrm{Hb}<10 \mathrm{~g} / \mathrm{dL}$ and $\mathrm{MCV}<80 \mathrm{fL}$, anaemia associated with malaria was defined as $\mathrm{Hb}<10 \mathrm{~g} / \mathrm{dL}$ and malaria parasitaemia and anaemia associated with stunting was defined as $\mathrm{Hb}<10 \mathrm{~g} / \mathrm{dL}$ with stunting. A clinical malaria episode was defined as parasitaemia and temperature $>37.5^{\circ} \mathrm{C}$. Anthropometry data i.e. height, and weight were transformed into height-for-age (HAZ), weight-for-age (WAZ), weight-for-height (WHZ) z-scores using the WHO z-anthro program, and categorised into stunting (HAZ<-2 SD), underweight (WAZ<-2 SD) and wasting (WHZ<-2 SD) respectively [21].

\subsection{Developmental Assessments}


At age 15 months, motor and cognitive abilities were assessed using measures that were developed or translated within the East African region. These included two measures of executive function, the A-not-B task and a self-control (delay inhibition) task, previously translated and used in rural Kenya [22]. Infants' language, self-care and recognition of self and others were determined using caregiver reports [22]. Finemotor and gross-motor function were tested using psychomotor ratings in the Kilifi Developmental Inventory [23]. The measures used at age 15 months are summarised in Supplementary Table 2. As previously reported, the measures had high inter-rater reliability, and principal components analysis revealed that psychomotor tasks loaded on the same component while cognitive measures loaded on another component [24]. For the current analyses, we grouped the 15-month scores into four domains: [1] executive function, a sum of A not B task and self-control scores; [2] psychomotor, a sum of fine-motor and gross-motor scores; [3] social cognition, a sum of self-care and recognition of self and others; and [4] language scores.

At age five years, cognitive and motor assessments were performed using 13 measures. In the current analyses, we excluded four tests (counting span, running memory, shapes task and tower of London) that were administered to only a small proportion $(<20 \%)$ of the children. For the remaining nine tests, we used principal components analysis to generate scores for three components of child development: verbal and non-verbal intelligence quotient (IQ), executive function (EF) and motor ability (Supplementary Table 3). We further excluded the tap one tap twice task and sentence repetition tests, which did not load well on the IQ, EF or motor ability components. Details of the translation and validation of all the tests are described elsewhere [25]. In a small pilot study, the tests had good internal consistency (Cronbach's alpha $=0.65-0.82)$ and testretest reliability (correlation coefficient $(r)=0.45-0.88)$ except the Wisconsin card sort test $(r=0.22)$ which was administered to only 19 children in the pilot study [25]. The tests used at age five years are summarized in Supplementary Table 4.

\subsection{Statistical Analyses}

Statistical analyses were conducted using STATA version 15.1 (StataCorp, College Station, TX 77845, United States of America). Participant socio-demographic and health characteristics, iron and haemoglobin profiles and developmental scores were described using means and standard deviations or confidence intervals, or median and interquartile ranges for continuous variables and proportions for binary variables. A total household asset score of six was derived using principal components analysis with one indicating lowest and six indicating highest household socioeconomic status.

All developmental scores at 15 months were skewed and were therefore inversely normal transformed. Developmental scores at five years were normally distributed. Univariable linear regression analysis and a Pvalue cut-off $<0.05$ were used to identify potential confounding factors to include as covariates in further analyses. To examine associations between anaemia/ iron status and developmental scores at 15 months and five years we then conducted multivariable linear regression analyses adjusted for the identified confounding factors. In secondary analyses we explored associations between iron profiles corrected for inflammation and malaria using a regression-correction approach proposed by the Biomarkers Reflecting Inflammation and Nutritional Determinants of Anemia (BRINDA) project, which accounts for the linear effects of inflammation and/or malaria on iron biomarkers $[5,26]$ and five-year developmental scores. We were not able to explore the effects of severe anaemia on development due to limited power as only $32(3.4 \%)$ children had severe anaemia. We were also not able to evaluate the effects of different aetiologies of anaemia as most children who had anaemia associated with malaria or stunting also had microcytic anaemia. We performed subgroup analyses to explore the effects of combined maternal and child anaemia on developmental scores at 15 months. We further fitted multivariable fractional polynomial models to allow for nonlinear effects of maternal or child $\mathrm{Hb}$ levels on developmental scores at 15 months.

\section{Results}

\subsection{Characteristics of Study Participants}


medRxiv preprint doi: https://doi.org/10.1101/2022.03.02.22271741; this version posted March 3, 2022. The copyright holder for this preprint (which was not certified by peer review) is the author/funder, who has granted medRxiv a license to display the preprint in perpetuity.

It is made available under a CC-BY 4.0 International license .

We included 933 mothers with $\mathrm{Hb}$ measurements during pregnancy and 933 children with $\mathrm{Hb}$ measurements at one year and developmental scores at 15 months in analyses for aim one. A total of 726 children had complete data for analyses assessing associations between Hb levels/any moderate anaemia event below five years and developmental scores at five years (aim two), while 530 children had iron profiles at two years and developmental scores at five years and were included in the analyses for aim three. Mean maternal age was 24 years, about half of the women had secondary or tertiary education, and over $50 \%$ had two to four children at enrolment (Supplementary Table 5). All maternal characteristics were similar for all three analysis groups (Supplementary Table 5). Table 1 shows the characteristics of children who were included in each analysis. Approximately half of the children were male. Stunting was more common (13.9\% at 12 months, 26.3\% at 5 years) than underweight or wasting in this study population. Malaria was common, with $28 \%$ and $59 \%$ of children having had at least one episode of clinical malaria in infancy and in the first five years, respectively. Approximately $5 \%$ of 12 -month-olds and $14 \%$ of 5 -year-olds had asymptomatic malaria parasitaemia at annual review. At one year $2.4 \%$ of children had helminth infections; $19.3 \%$ had helminthic infections at five years (Table 1).

Table 1: Participant Characteristics

\begin{tabular}{|c|c|c|c|}
\hline Variable & $\begin{array}{l}\text { Analysis for aim } \\
\text { 1; maternal } \mathrm{Hb} \\
\text { during pregnancy, } \\
\text { child } \mathrm{Hb} 12 \mathrm{mths} \\
\text { and development } \\
\text { at } 15 \text { months } \\
(\mathrm{n}=933)\end{array}$ & $\begin{array}{l}\text { Analysis for aim 2; } \\
\text { annual } \mathrm{Hb} \text { and } \\
\text { development at } 5 \\
\text { years }(n=726)\end{array}$ & $\begin{array}{l}\text { Analysis for aim 3; } \\
\text { iron status at } 2 \\
\text { years and } \\
\text { development at } 5 \\
\text { years }(n=530)\end{array}$ \\
\hline Age at $\mathrm{Hb}$ / iron assessment, mean (SD) & 12 months & Annually (1-5years) & $2.4(0.8)$ years \\
\hline Age at developmental assessment, mean (SD) & $15.4(0.5)$ months & $5.0(0.8)$ years & $5.0(0.8)$ years \\
\hline Sex, male, n/total (\%) & $470 / 932(50.4)$ & $355 / 724(49.0)$ & $260 / 530(49.1)$ \\
\hline *Any malaria parasitaemia, n (\%) & $46 / 929(5.0)$ & $102 / 726(14.1)$ & $72 / 530(13.7)$ \\
\hline \multicolumn{4}{|l|}{ **Clinical malaria episodes, $\mathrm{n}(\%)$} \\
\hline None & $674 / 932(72.3)$ & $297 / 722(41.2)$ & $216 / 530(40.8)$ \\
\hline$\geq 1$ & $258 / 932(27.7)$ & $425 / 722(58.9)$ & $314 / 530(59.3)$ \\
\hline \multicolumn{4}{|l|}{$* * *$ Helminthic infections } \\
\hline Schistosomiasis, $\mathrm{n} /$ total (\%) & $0 / 877(0)$ & $28 / 726(3.9)$ & $15 / 530(2.8)$ \\
\hline Hookworm, n/total (\%) & $2 / 877(0.2)$ & $19 / 726(2.6)$ & $13 / 530(2.5)$ \\
\hline Any worm infection, $\mathrm{n} /$ total (\%) & $21 / 877(2.4)$ & $140 / 726(19.3)$ & $101 / 530(19.1)$ \\
\hline Treatment with albendazole, $\mathrm{n} /$ total $(\%)$ & $462 / 930(49.7)$ & $354 / 724(48.9)$ & $254 / 530(47.9)$ \\
\hline \multicolumn{4}{|l|}{$\begin{array}{l}\text { Nutritional status at developmental } \\
\text { assessment }\end{array}$} \\
\hline Stunting, n/total (\%) & $127 / 921(13.8)$ & $187 / 710(26.3)$ & $136 / 520(26.2)$ \\
\hline Underweight, n/total (\%) & 79/932 (8.9) & $70 / 714(9.8)$ & $59 / 523(11.3)$ \\
\hline Wasting, n/total (\%) & 39/921 (4.2) & $53 / 713(7.4)$ & $40 / 523(7.7)$ \\
\hline \multicolumn{4}{|l|}{ Household socioeconomic status, n/total (\%) } \\
\hline 1 (lowest) & $51 / 916(5.6)$ & $46 / 713(6.5)$ & $30 / 521(5.8)$ \\
\hline 2 & $68 / 916(7.4)$ & $45 / 713(6.3)$ & $38 / 521(13.1)$ \\
\hline 3 & $287 / 916(31.3)$ & $219 / 713(30.7)$ & $163 / 521(31.3)$ \\
\hline 4 & $268 / 916(29.3)$ & $210 / 713(29.5)$ & $143 / 521(27.5)$ \\
\hline 5 & $189 / 916(20.6)$ & $142 / 713(19.9)$ & $108 / 521(20.7)$ \\
\hline 6 (highest) & $53 / 916(5.8)$ & $51 / 713(7.2)$ & $39 / 521(7.5)$ \\
\hline
\end{tabular}


medRxiv preprint doi: https://doi.org/10.1101/2022.03.02.22271741; this version posted March 3, 2022. The copyright holder for this preprint (which was not certified by peer review) is the author/funder, who has granted medRxiv a license to display the preprint in perpetuity.

It is made available under a CC-BY 4.0 International license .

$\mathrm{Hb}$, haemoglobin; SD, standard deviation. Stunting, underweight and wasting were defined as height-for-age $\mathrm{Z}$ scores $<-2 \mathrm{SD}$, weight-for-age Z scores $<-2$ SD and weight-for-height Z scores $<-2$ SD respectively. Household socioeconomic status was derived using principal components analysis as a composite of building materials of the home, number of rooms and items owned. A total asset score was calculated with 1 indicating lowest and 6 indicating highest household socioeconomic status. *All children were tested annually for asymptomatic malaria parasitaemia. **clinical malaria episodes were recorded for symptomatic children during longitudinal follow-up. *** All children were tested annually for helminthic infections during longitudinal follow-up.

The prevalence of ID and anaemia and the distribution of individual iron markers, $\mathrm{Hb}$ and CRP are shown in Table 2. About $36 \%$ and $15.8 \%$ of mothers had mild or moderate anaemia during pregnancy, respectively. In children, the prevalence of mild, moderate, and severe anaemia at 12 months of age was $76.3 \%, 46.7 \%$ and $3.4 \%$ respectively and decreased to $13.6 \%, 4.4 \%$ and $0.6 \%$ at five years of age, respectively. The prevalence of microcytic anaemia and anaemia associated with stunting or malaria at 12 months was $45.8 \%, 7.3 \%$ and $4.3 \%$ respectively and decreased to $2.5 \%, 1.9 \%$ and $1.4 \%$ at five years of age, respectively. About $47.1 \%$ of children had at least one episode of moderate anaemia during the one to five years of follow-up while at age 2 years, almost a third of children had ID and $18.6 \%$ had IDA.

Table 2: Distribution of haemoglobin levels and markers of iron status and inflammation

\begin{tabular}{|c|c|}
\hline \\
\hline Anaemia & \\
\hline Moderate anaemia at age $1, \mathrm{n} /$ total $(\%)$ & $436 / 933(46.7)$ \\
\hline Moderate anaemia at age $2, \mathrm{n} /$ total $(\%)$ & $127 / 615(20.7)$ \\
\hline Moderate anaemia at age $3, \mathrm{n} /$ total $(\%)$ & $26 / 641(4.1)$ \\
\hline Moderate anaemia at age $4, \mathrm{n} /$ total $(\%)$ & $13 / 399(3.3)$ \\
\hline Moderate anaemia at age $5, \mathrm{n} /$ total $(\%)$ & $31 / 713(4.4)$ \\
\hline Any moderate anaemia event from 1-5 years of age, n/total $(\%)$ & $342 / 726(47.1)$ \\
\hline Any mild anaemia event from $1-5$ years of age, n/total (\%) & $550 / 726(75.8)$ \\
\hline Microcytic anaemia at 12 months of age, n/total (\%) & $427 / 933(45.8)$ \\
\hline Anaemia associated with malaria at 12 months of age, n/total (\%) & $40 / 929(4.3)$ \\
\hline Anaemia associated with stunting at 12 months of age, n/total (\%) & $67 / 921(7.3)$ \\
\hline \multicolumn{2}{|l|}{ Annual haemoglobin (Hb) levels } \\
\hline $\mathrm{Hb}$ at age $1(\mathrm{~g} / \mathrm{dL})$, mean $(95 \% \mathrm{CI})(\mathrm{n}=933)$ & $9.9(9.8,10.0)$ \\
\hline $\mathrm{Hb}$ at age $2(\mathrm{~g} / \mathrm{dL})$, mean $(95 \% \mathrm{CI})(\mathrm{n}=615)$ & $10.9(10.8,11.0)$ \\
\hline $\mathrm{Hb}$ at age $3(\mathrm{~g} / \mathrm{dL})$, mean $(95 \% \mathrm{CI})(\mathrm{n}=641)$ & $11.7(11.6,11.8)$ \\
\hline $\mathrm{Hb}$ at age $4(\mathrm{~g} / \mathrm{dL})$, mean $(95 \% \mathrm{CI})(\mathrm{n}=399)$ & $12.1(11.7,12.6)$ \\
\hline $\mathrm{Hb}$ at age $5(\mathrm{~g} / \mathrm{dL})$, mean $(95 \% \mathrm{CI})(\mathrm{n}=713)$ & $12.0(11.9,12.1)$ \\
\hline \multicolumn{2}{|l|}{ Iron status } \\
\hline Iron deficiency at 2 years of age, $\mathrm{n} /$ total $(\%)$ & $152 / 490(31.0)$ \\
\hline Iron deficiency anaemia at 2 years of age, $\mathrm{n} /$ total $(\%)$ & $82 / 441(18.6)$ \\
\hline \multicolumn{2}{|l|}{ Iron and inflammation biomarkers at 2 years of age } \\
\hline Ferritin $(\mu \mathrm{g} / \mathrm{L})$, mean $(95 \% \mathrm{CI})(\mathrm{n}=495)$ & $21.7(19.8,23.7)$ \\
\hline Transferrin $(\mathrm{g} / \mathrm{L})$, mean $(95 \% \mathrm{CI})(\mathrm{n}=517)$ & $2.7(2.7,2.8)$ \\
\hline $\operatorname{sTfR}(\mathrm{mg} / \mathrm{L})$ mean $(95 \% \mathrm{CI})(\mathrm{n}=518)$ & $6.3(5.9,6.7)$ \\
\hline Hepcidin $(\mu \mathrm{g} / \mathrm{L})$ mean $(95 \% \mathrm{CI})(\mathrm{n}=516)$ & $7.8(7.0,8.6)$ \\
\hline C-reactive protein $(\mathrm{mg} / \mathrm{L})$ mean $(95 \% \mathrm{CI})(\mathrm{n}=519)$ & $1.3(1.2,1.5)$ \\
\hline \multicolumn{2}{|l|}{ Maternal $\mathrm{Hb} /$ anaemia status at enrolment in pregnancy } \\
\hline Hb levels $(\mathrm{g} / \mathrm{dL})$, mean $(95 \% \mathrm{CI})(\mathrm{n}=933)$ & $11.4(11.3,11.4)$ \\
\hline Mild anaemia, n/total (\%) & $336 / 933(36.0)$ \\
\hline Moderate anaemia, n/total (\%) & $147 / 933(15.8)$ \\
\hline
\end{tabular}


$\mathrm{CI}$, confidence interval; $\mathrm{Hb}$, haemoglobin; SD, standard deviation; sTfR, soluble transferrin receptor. Iron deficiency was defined as ferritin $<12 \mu \mathrm{g} / \mathrm{L}$ in the absence of inflammation or $<30 \mu \mathrm{g} / \mathrm{L}$ in the presence of inflammation $(\mathrm{CRP}>5$ $\mathrm{mg} / \mathrm{L}$ ); Iron deficiency anaemia was defined as the presence of both iron deficiency and anaemia. Moderate and mild anaemia were defined as haemoglobin $<10 \mathrm{~g} / \mathrm{dL}$ and $<11 \mathrm{~g} / \mathrm{dl}$, respectively. Microcytic anaemia was defined as haemoglobin levels $<10 \mathrm{~g} / \mathrm{dL}$ and mean corpuscular volume $<80 \mathrm{fL}$, anaemia associated with malaria was defined as haemoglobin levels $<10 \mathrm{~g} / \mathrm{dL}$ and malaria parasitaemia, anaemia associated with stunting was defined as haemoglobin levels $<10 \mathrm{~g} / \mathrm{dL}$ and stunting. All haemoglobin measures were adjusted for change in altitude (1000 $\mathrm{m}$ above sea level). Mean values are geometric means except for transferrin and haemoglobin which are arithmetic means. Children with missing developmental scores were excluded.

\subsection{Associations between Participant Characteristics and Developmental Scores at 15 Months and Five Years}

Median and interquartile ranges for the individual developmental scores at 15 months and 5 years are shown in Supplementary Table 6. In multivariable analyses, girls had lower psychomotor scores at 15 months and higher IQ and motor ability scores at five years compared to boys. Malaria parasitaemia at annual review was associated with lower IQ at five years. Stunted children had lower psychomotor, social cognition and language scores at 15 months and lower executive function scores at 5 years compared to non-stunted children. Low socioeconomic status was associated with lower language scores at 15 months and lower executive function at five years, while secondary or tertiary maternal education was associated with higher motor scores at 15 months and higher IQ and executive function at five years compared to primary or no maternal education, as previously reported [24, 27] (Supplementary Tables 7 and 8).

\subsection{Anaemia during Pregnancy is Associated with Reduced Psychomotor Scores in Children at 15 Months}

In multivariable analyses, lower maternal $\mathrm{Hb}$ levels and mild or moderate anaemia during pregnancy were independently associated with lower psychomotor scores at 15 months after controlling for infant $\mathrm{Hb}$ levels, but were not associated with executive function, social cognition, or language scores (Tables 3 and 4).

Table 3: Univariable and multivariable linear regression results for the associations between maternal and child haemoglobin levels and developmental scores at 15 months.

\begin{tabular}{|l|l|l|l|l|l|l|}
\hline Developmental domain & $\mathbf{n}$ & $\begin{array}{l}\text { Univariable } \\
\text { model } \boldsymbol{\beta} \\
\mathbf{9 5 \%} \mathbf{C I})\end{array}$ & $\begin{array}{l}\mathbf{P} \\
\text { value }\end{array}$ & $\begin{array}{l}\mathbf{n} \\
\text { Multivariable } \\
\text { model* } \boldsymbol{\beta} \text { (95\% } \\
\mathbf{C I})\end{array}$ & P value \\
\hline Maternal haemoglobin levels and developmental scores at 15 months \\
\hline $\begin{array}{l}\text { Executive function (A not B + } \\
\text { self-control) }\end{array}$ & 686 & $-0.01(-0.06,0.04)$ & 0.71 & 619 & $-0.002(-0.06,0.05)$ & 0.93 \\
\hline $\begin{array}{l}\text { Psychomotor (fine motor + } \\
\text { gross motor) }\end{array}$ & 915 & $0.06(0.02,0.11)$ & 0.01 & 828 & $0.05(0.0002,0.09)$ & 0.05 \\
\hline $\begin{array}{l}\text { Social cognition (recognition } \\
\text { of self and others + self-care) }\end{array}$ & 933 & $0.03(-0.1,0.07)$ & 0.19 & 843 & $0.02(-0.03,0.06)$ & 0.50 \\
\hline \begin{tabular}{l|l|l|l|l|l|l|} 
Language \\
Child haemoglobin levels at 12 months and developmental scores at 15 months
\end{tabular} & 933 & $0.02(-0.02,0.06)$ & 0.08 & 843 & $-0.01(-0.05,0.04)$ & 0.81 \\
\hline $\begin{array}{l}\text { Executive function (A not B + } \\
\text { self-control) }\end{array}$ & 686 & $0.01(-0.04,0.07)$ & 0.60 & 619 & $0.03(-0.03,0.09)$ & 0.28 \\
\hline $\begin{array}{l}\text { Psychomotor (fine motor + } \\
\text { gross motor) }\end{array}$ & 915 & $0.07(0.03,0.12)$ & 0.001 & 828 & $0.07(0.02,0.12)$ & 0.003 \\
\hline $\begin{array}{l}\text { Social cognition (recognition } \\
\text { of self and others + self-care) }\end{array}$ & 933 & $0.03(-0.4,0.10)$ & 0.40 & 843 & $0.13(-0.10,0.36)$ & 0.28 \\
\hline
\end{tabular}


medRxiv preprint doi: https://doi.org/10.1101/2022.03.02.22271741; this version posted March 3, 2022. The copyright holder for this preprint (which was not certified by peer review) is the author/funder, who has granted medRxiv a license to display the preprint in perpetuity.

It is made available under a CC-BY 4.0 International license .

\begin{tabular}{|l|l|l|l|l|l|l|}
\hline Language & 933 & $0.04(-0.01,0.08)$ & 0.09 & 843 & $0.05(0.002,0.10)$ & 0.04 \\
\hline
\end{tabular}

CI, confidence interval. *Multivariable models were adjusted for age at developmental assessment, sex, stunting, socioeconomic status, maternal education, helminthic infections, and malaria parasitaemia. Multivariable models are additionally adjusted for child haemoglobin levels at 12 months or maternal haemoglobin levels during pregnancy. All developmental scores at 15 months were inverse transformed to normalize their distributions.

\subsection{Lower Haemoglobin Levels at 12 Months of Age are Associated with Reduced Psychomotor and Language Scores at 15 Months.}

In children, lower $\mathrm{Hb}$ levels at 12 months were independently associated with reduced psychomotor and language scores after controlling for maternal $\mathrm{Hb}$ levels and other covariates at 15 months in adjusted models (Table 3). Moderate anaemia at 12 months was similarly associated with reduced psychomotor scores at 15 months (Table 4). Hb levels and anaemia were not associated with executive function or social cognition. We found no evidence of non-linear associations between maternal or child $\mathrm{Hb}$ levels and developmental scores at 15 months using fractional polynomial models.

In subgroup analyses, combined maternal anaemia in pregnancy and child anaemia at 12 months was strongly associated with reduced psychomotor scores at 15 months (Table 4). We found an interaction between maternal and child anaemia in predicting psychomotor scores so that the combined effect of both being born to a mother who was anaemic during the pregnancy and having anaemia in childhood was larger than the product of the individual effects of each condition $(\beta=-0.28 ; 95 \% \mathrm{CI}$ : $-0.56,-0.01 ; \mathrm{P}$ value $=0.04)$. We did not find any interactions between maternal and child anaemia in predicting other developmental scores.

Table 4: Multivariable linear regression results for associations between maternal and child anaemia and developmental scores at 15 months

\begin{tabular}{|c|c|c|c|c|c|c|}
\hline Developmental domain & $\mathbf{n}$ & $\begin{array}{l}\text { Univariable } \\
\text { model } \beta \\
(95 \% \mathrm{CI})\end{array}$ & P value & $\mathbf{n}$ & $\begin{array}{l}\text { Multivariable } \\
\text { model* } \beta(95 \% \\
\text { CI) }\end{array}$ & P value \\
\hline \multicolumn{7}{|c|}{ Mild maternal anaemia during pregnancy and developmental scores at 15 months $(n=336 / 933)$} \\
\hline $\begin{array}{l}\text { Executive function (A not } \\
\text { B + self-control) }\end{array}$ & 686 & $-0.03(-0.19,0.12)$ & 0.68 & 619 & $0.03(-0.20,0.13)$ & 0.68 \\
\hline $\begin{array}{l}\text { Psychomotor (fine motor } \\
\text { + gross motor) }\end{array}$ & 915 & $\begin{array}{l}-0.19(-0.32,- \\
0.05)\end{array}$ & 0.01 & 828 & $\begin{array}{l}-0.14(-0.27,- \\
0.002)\end{array}$ & 0.05 \\
\hline $\begin{array}{l}\text { Social cognition } \\
\text { (recognition of self and } \\
\text { others +self-care) }\end{array}$ & 933 & $-0.04(-0.17,0.09)$ & 0.55 & 843 & $0.02(-0.12,0.16)$ & 0.77 \\
\hline Language & 933 & $-0.01(-0.14,0.12)$ & 0.88 & 843 & $0.05(-0.09,0.19)$ & 0.48 \\
\hline \multicolumn{7}{|c|}{ Moderate child anaemia at 12 months and developmental scores at 15 months $(436 / 933)^{\mathrm{a}}$} \\
\hline $\begin{array}{l}\text { Executive function (A not } \\
\text { B + self-control) }\end{array}$ & 686 & $\begin{array}{l}-0.002(-0.15 \\
0.15)\end{array}$ & 0.97 & 619 & $-0.03(-0.20,0.13)$ & 0.70 \\
\hline $\begin{array}{l}\text { Psychomotor (fine motor } \\
+ \text { gross motor) }\end{array}$ & 915 & $\begin{array}{l}-0.18(-0.31,- \\
0.06)\end{array}$ & 0.01 & 828 & $-0.21(-0.35,-0.08)$ & 0.002 \\
\hline $\begin{array}{l}\text { Social cognition } \\
\text { (recognition of self and } \\
\text { others + self-care) }\end{array}$ & 933 & $\begin{array}{l}-0.16(-0.29,- \\
0.03)\end{array}$ & 0.01 & 843 & $-0.59(-1.24,0.05)$ & 0.07 \\
\hline Language & 933 & $-0.05(-0.18,0.08)$ & 0.45 & 846 & $-0.09(-0.23,0.05)$ & 0.19 \\
\hline
\end{tabular}


medRxiv preprint doi: https://doi.org/10.1101/2022.03.02.22271741; this version posted March 3, 2022. The copyright holder for this preprint (which was not certified by peer review) is the author/funder, who has granted medRxiv a license to display the preprint in perpetuity.

It is made available under a CC-BY 4.0 International license .

\begin{tabular}{|l|l|l|l|l|l|l|}
\hline $\begin{array}{l}\text { Executive function (A not } \\
\text { B + self-control) }\end{array}$ & 686 & $-0.08(-0.27,0.11)$ & 0.41 & 619 & $-0.10(-0.30,0.11)$ & 0.36 \\
\hline $\begin{array}{l}\text { Psychomotor (fine motor } \\
\text { + gross motor) }\end{array}$ & 915 & $\begin{array}{l}-0.36(-0.52,- \\
0.19)\end{array}$ & 0.0002 & 828 & $-0.35(-0.52,-0.19)$ & 0.00004 \\
\hline $\begin{array}{l}\text { Social cognition } \\
\text { (recognition of self and } \\
\text { others +self-care) }\end{array}$ & 933 & $-0.12(-0.29,0.04)$ & 0.14 & 843 & $-0.08(-0.25,0.10)$ & 0.39 \\
\hline Language & 933 & $0.02(-0.14,0.19)$ & 0.78 & 843 & $0.03(-0.14,0.21)$ & 0.71 \\
\hline
\end{tabular}

$\mathrm{CI}$, confidence interval. Mild and moderate anaemia were defined as haemoglobin levels $<11 \mathrm{~g} / \mathrm{dL}$ and $<10 \mathrm{~g} / \mathrm{dL}$ respectively, adjusting for high altitude $(1000 \mathrm{~m}$ above sea level). *Multivariable models were adjusted for age at developmental assessment, sex, stunting, socioeconomic status, maternal education, helminthic infections and malaria parasitaemia. Multivariable models were additionally adjusted for child haemoglobin levels at 12 months or maternal haemoglobin levels during pregnancy. All developmental scores at 15 months were inverse transformed to normalize their distributions. ${ }^{a}$ Presented results are for associations with moderate child anaemia at 12 months as mild anaemia was very common $\left(76.3 \%\right.$ ) among children at that age. ${ }^{b}$ Combined anaemia is mild maternal anaemia during pregnancy and moderate child anaemia.

3.5. Haemoglobin Levels and Anaemia in Mothers and Children are not Associated with Developmental Scores at Five Years.

We observed no evidence of association between maternal or child $\mathrm{Hb}$ levels, or any moderate anaemia event between one to five years of age, and verbal and non-verbal IQ, executive function, or motor ability at five years of age (Table 5, Supplementary Table 9, and Supplementary Figure 1).

Table 5: Univariable and multivariable linear regression results for the association between haemoglobin levels or anaemia and developmental scores at 5 years.

\begin{tabular}{|c|c|c|c|c|c|c|}
\hline Developmental domain & $\mathbf{n}$ & $\begin{array}{l}\text { Univariable } \\
\text { model } \quad \beta(95 \% \\
\text { CI) }\end{array}$ & $\begin{array}{l}P \\
\text { value }\end{array}$ & $\mathbf{n}$ & $\begin{array}{l}\text { Multivariable } \\
\text { model* } \beta(95 \% \\
\text { CI) }\end{array}$ & $\begin{array}{l}P \\
\text { value }\end{array}$ \\
\hline \multicolumn{7}{|c|}{ Haemoglobin levels at 5 years and developmental scores at 5 years } \\
\hline Verbal and non-verbal IQ & 713 & $\begin{array}{r}0.0002(-0.06 \\
0.06)\end{array}$ & 0.99 & 681 & $\begin{array}{r}-0.002(-0.06 \\
0.06)\end{array}$ & 0.96 \\
\hline Executive function & 713 & $-0.04(-0.10,0.02)$ & 0.15 & 681 & $\begin{array}{r}-0.06(-0.11 \\
0.002)\end{array}$ & 0.06 \\
\hline Motor ability & 713 & $\begin{array}{r}-0.004(-0.05 \\
0.05) \\
\end{array}$ & 0.88 & 681 & $\begin{array}{r}-0.001(-0.05 \\
0.05) \\
\end{array}$ & 0.99 \\
\hline \multicolumn{7}{|c|}{ Any moderate anaemia event below 5 years and developmental scores at 5 years } \\
\hline Verbal and non-verbal IQ & 726 & $-0.18(-0.31,0.08)$ & 0.25 & 693 & $0.02(-0.19,0.22)$ & 0.22 \\
\hline Executive function & 726 & $0.01(-0.18,0.20)$ & 0.91 & 693 & $0.11(-0.08,0.30)$ & 0.25 \\
\hline Motor ability & 726 & $-0.04(-0.19,0.12)$ & 0.66 & 693 & $0.04(-0.13,0.20)$ & 0.67 \\
\hline
\end{tabular}

$\mathrm{CI}$, confidence interval. Moderate anaemia was defined as haemoglobin levels $<10 \mathrm{~g} / \mathrm{dL}$ adjusting for change in altitude (1000 $\mathrm{m}$ above sea level). *The multivariable models were adjusted for age at developmental assessment, sex, stunting, socioeconomic status, maternal education, maternal haemoglobin levels during pregnancy, helminthic infections and malaria parasitaemia.

\subsection{Iron Status at Two Years was not Associated with Developmental Scores at Five Years.}

We found no evidence of an association between iron status at two years and developmental scores at five years of age in multivariable analyses. In univariable analyses, we observed associations between ID, ferritin and transferrin levels and executive function scores but these effects were not observed after adjusting for potential confounders (Table 6). Similarly, in secondary analyses we observed no associations between iron profiles and developmental scores at five years of age after correcting markers of iron status for inflammation and malaria using the BRINDA approach [26] (Supplementary Table 10). 
medRxiv preprint doi: https://doi.org/10.1101/2022.03.02.22271741; this version posted March 3, 2022. The copyright holder for this preprint

(which was not certified by peer review) is the author/funder, who has granted medRxiv a license to display the preprint in perpetuity.

It is made available under a CC-BY 4.0 International license .

Table 6: Multivariable linear regression results for the association between measures of iron status and anaemia at two years of age and cognitive and motor scores at five years of age.

\begin{tabular}{|l|l|l|l|}
\hline Iron parameter & $\mathbf{n}$ & $\begin{array}{l}\text { Multivariable model, } \\
\boldsymbol{\beta}(\mathbf{9 5} \% \mathbf{C I})\end{array}$ & P value \\
\hline Verbal/ non-verbal IQ \\
\hline ID & 471 & $0.09(-0.16,0.35)$ & 0.45 \\
\hline IDA & 454 & $-0.02(-0.37,0.32)$ & 0.90 \\
\hline Ferritin $(\mu \mathrm{g} / \mathrm{L})$ & 471 & $-0.12(-0.25,0.02)$ & 0.09 \\
\hline $\begin{array}{l}\text { Transferrin } \\
(\mathrm{g} / \mathrm{L})\end{array}$ & 495 & $0.14(0.06,0.33)$ & 0.18 \\
\hline sTfR $(\mathrm{mg} / \mathrm{L})$ & 490 & $-0.15(-0.32,0.02)$ & 0.09 \\
\hline Hepcidin $(\mu \mathrm{g} / \mathrm{L})$ & 489 & $-0.03(-0.14,0.07)$ & 0.54 \\
\hline Executive function & 471 & $0.21(-0.04,0.45)$ & 0.09 \\
\hline ID & 454 & $-0.11(-0.44,0.22)$ & 0.53 \\
\hline IDA & 471 & $-0.11(-0.24,0.02)$ & 0.11 \\
\hline Ferritin $(\mu \mathrm{g} / \mathrm{L})$ & 495 & $0.13(-0.06,0.32)$ & 0.18 \\
\hline $\begin{array}{l}\text { Transferrin } \\
(\mathrm{g} / \mathrm{L})\end{array}$ & 490 & $-0.05(-0.21,0.11)$ & 0.54 \\
\hline sTfR $(\mathrm{mg} / \mathrm{L})$ & 489 & $-0.05(-0.14,0.05)$ & 0.32 \\
\hline Hepcidin $(\mu \mathrm{g} / \mathrm{L})$ & 4 & \\
\hline Motor ability & 471 & $0.12(-0.09,0.34)$ & 0.25 \\
\hline ID & 454 & $0.09(-0.19,0.38)$ & 0.52 \\
\hline IDA & 471 & $-0.07(-0.19,0.04)$ & 0.20 \\
\hline Ferritin $(\mu \mathrm{g} / \mathrm{L})$ & 495 & $0.01(-0.18,0.15)$ & 0.87 \\
\hline $\begin{array}{l}\text { Transferrin } \\
(\mathrm{g} / \mathrm{L})\end{array}$ & 490 & $-0.07(-0.21,0.07)$ & 0.32 \\
\hline sTfR(mg/L) & 489 & $-0.04(-0.12,0.05)$ & 0.39 \\
\hline Hepcidin $(\mu \mathrm{g} / \mathrm{L})$ & 49.5 \\
\hline
\end{tabular}

CI, confidence interval; sTfR, soluble transferrin receptor; ID, iron deficiency; IDA, iron deficiency anaemia. ID was defined as plasma ferritin $<12 \mu \mathrm{g} / \mathrm{L}$ in the absence of inflammation or $<30 \mu \mathrm{g} / \mathrm{L}$ in the presence of inflammation (CRP $>5 \mathrm{mg} / \mathrm{L}$ ); Iron deficiency anaemia was defined as the presence of both iron deficiency and mild anaemia (haemoglobin $<11 \mathrm{~g} / \mathrm{dL}$ ). All haemoglobin measures were adjusted for change in altitude (1000 m above sea level). The multivariable models were adjusted for age at iron measurement, sex, stunting, inflammation, helminthic infections, socioeconomic status, maternal education, and malaria parasitaemia. Ferritin, sTfR, hepcidin and CRP levels were natural $\log (\ln )$ transformed to normalize their distribution.

\section{Discussion}

About 29.5 million pre-school children in Sub-Saharan Africa experience developmental delay [1]. Similar to previous findings in the same cohort, we observed associations between sex, household socioeconomic status, maternal education, stunting, malaria parasitaemia and developmental scores at 15 months and five years [24, 27]. Anaemia and lack of sufficient iron in early childhood are thought to impair the development of motor and cognitive functions. The present study examined the effect of maternal and child anaemia on developmental scores at 15 months and five years and iron deficiency (ID) at two years on developmental scores at five years in a birth cohort of pre-school Ugandan children. About $36 \%$ and $15.8 \%$ of mothers had mild $(\mathrm{Hb}<11 \mathrm{~g} / \mathrm{dL})$ and moderate anaemia $(\mathrm{Hb}<10 \mathrm{~g} / \mathrm{dL})$ respectively during pregnancy. At one year of age, $76.3 \%, 46.7 \%$ and $3.4 \%$ of children had mild, moderate, and severe anaemia, respectively, while at five years $13.6 \%, 4.4 \%$ and $0.6 \%$ of children had mild, moderate and severe anaemia, respectively. At two years of age $31.2 \%$ and $18.6 \%$ of children had ID and IDA, respectively. Low Hb levels and anaemia in mothers during pregnancy and at 12 months in children were associated with reduced psychomotor scores at 15 months. Lower 
$\mathrm{Hb}$ levels at 12 months were also associated with reduced language scores at 15 months. However, we did not observe associations between maternal or child $\mathrm{Hb}$ levels, or any moderate anaemia event below five years and cognitive or motor scores at five years. We also found no evidence that iron profiles at two years predicted developmental scores at five years.

Lower maternal $\mathrm{Hb}$ levels and anaemia during pregnancy were associated with reduced psychomotor scores at 15 months after controlling for potential confounders including infant $\mathrm{Hb}$ levels. In contrast to our findings, one study utilizing datasets from two mother-child cohorts in Ghana $(n=1023)$ and Malawi $(n=675)$ reported no associations between maternal $\mathrm{Hb}$ or iron status and motor or language development in children at 18 months, which might be explained by the mothers receiving lipid-based nutrient supplementation, including iron and folic acid during pregnancy [14]. A cohort study of Beninese mother-child pairs ( $n=636)$ reported an inverted U-shaped association between maternal $\mathrm{Hb}$ levels and infant gross motor scores with maternal $\mathrm{Hb}$ levels 9-11 g/dL being optimal for gross motor development [15]. However, we observed that maternal $\mathrm{Hb}$ levels above $11 \mathrm{~g} / \mathrm{dl}$ were associated with improved psychomotor scores and did not identify a non-linear relationship between maternal $\mathrm{Hb}$ levels and developmental scores in our study. Similar to our study, they did not observe an association between maternal $\mathrm{Hb}$ and language scores at one year [15]. Low maternal Hb levels may affect child psychomotor scores through effects on foetal physiological functions that affect brain development in utero increasing the child's susceptibility to developmental delay after birth [28].

In the current study, we found that low $\mathrm{Hb}$ levels and moderate anaemia in infancy were associated with reduced psychomotor scores at 15 months of age. Our findings agree with two separate cross-sectional studies $(\mathrm{n}=1417)$ that reported associations between anaemia $(\mathrm{Hb}<10 \mathrm{~g} / \mathrm{dL})$, ID, and IDA and poor motor ability in Zanzibari children aged five to 19 months [29, 30]. Similarly, one small cross-sectional study (n=102) in Indonesia found that children with anaemia $(\mathrm{Hb}<11 \mathrm{~g} / \mathrm{dL})$ had lower fine motor scores compared to nonanaemic children at one to two years of age [31]. In contrast to our findings, a cross-sectional study of sixmonth-old South African children $(\mathrm{n}=750)$ reported no associations between anaemia $(\mathrm{Hb}<11 \mathrm{~g} / \mathrm{dL})$ and psychomotor scores [32]. Fewer children had mild anaemia (36.4\%) in that study population compared to our study $(76.3 \%)$ and they did not explore the effects of moderate anaemia which may explain the disparity in findings. The combined effects of anaemia during pregnancy and in infancy had the largest impact, so that anaemia during both time periods resulted in a much larger reduction in psychomotor development. This coincides with the period of rapid brain development, from conception up to the first 1000 days after birth [33]. Exposure to anaemia during this period may have detrimental effects on brain processes involved in psychomotor development. Anaemia may also affect psychomotor function through associated symptoms such as withdrawal and lethargy.

We similarly observed an association between higher $\mathrm{Hb}$ levels at one year and higher language scores at 15 months but found no associations with executive function or social cognition scores. In line with our findings, one study utilizing data from two child cohorts in Malawi $(n=1385)$ and Burkina Faso $(n=1122)$ reported an association between Hb levels and language development at 18 months [14]. In contrast, one cross-sectional study of 226 Egyptian children aged four to six years reported no association between IDA and language scores [34]. In contrast to epidemiological studies, animal studies consistently indicate that iron may influence brain processes involved in language function through its roles in myelination and neurotransmission in the hippocampus and the cerebellum, regions that mediate attention, memory and learning processes [35-37]. The causes of anaemia are multifactorial among children living in Africa and it is possible that anaemia itself or anaemia due to a specific cause may impair psychomotor development. In our study microcytic anaemia, which may have indicated ID, was common (46\% of children) at 12 months of age and anaemia associated with stunting or malaria was less prevalent ( $7.4 \%$ and $4.3 \%$, respectively). However, we were not able to ascertain associations with specific causes of anaemia in infancy as most the children who had anaemia associated with stunting or malaria also had microcytic anaemia.

We found no associations between $\mathrm{Hb}$ levels or moderate anaemia below five years and developmental scores at five years despite lower $\mathrm{Hb}$ levels influencing development at 15 months. In contrast with our findings, two large cross-sectional studies of Ecuadorean $(n=3153)$ and Chinese $(n=1293)$ children aged three to six years reported associations between anaemia $(\mathrm{Hb}<11 \mathrm{~g} / \mathrm{dL})$ and poor cognitive development $[38,39]$. It is likely 
that the causes of anaemia may differ in Ugandan compared to Ecuadorean and Chinese children. Why might $\mathrm{Hb}$ levels or anaemia influence developmental scores at 15 months but not at five years of age? As previously observed in African children, fewer children were moderately anaemic at 5 years of age (4.4\% compared to $46.7 \%$ at one year) and numbers were insufficient for subgroup analyses. It is possible that the effects of anaemia on psychomotor and language scores observed in infancy improved as anaemia resolved with increasing age. Additionally, the differing effects of anaemia on development at the two time-points may be due to the influence of changes in risk factors such as household socioeconomic status, nutritional changes and preschool experience.

We found no evidence of association between iron status at 2 years and cognitive or motor scores at five years in agreement with one cross-sectional study of 541 Ethiopian children aged 54 to 60 months which reported no association between ID (serum ferritin $<12 \mu \mathrm{g} / 1$ ) and cognitive scores [40]. Since inflammation and malaria alter measures of iron status, we further corrected iron biomarkers for inflammation and malaria using the BRINDA approach, but our findings were similar after this adjustment [26]. Other studies in older children provide mixed evidence for the effects of iron status on cognitive and motor development. One cohort study of 143 Icelandic children aged six years reported no associations between iron status and cognitive and motor development [41] while two observational studies in Turkey $(n=172)$ and Chile $(n=163)$ reported associations between IDA and cognitive and motor scores in children aged six months to six years [42, 43]. It is possible that the effects of ID are most marked during infancy when brain development is more rapid. The lack of association observed in our study may in part be because of the long interval between iron measurement and developmental assessments as the iron status of children may have improved during the three-year interval and the effects of previous deficits may have declined or been overtaken by other factors [5]. Two crosssectional studies in 1417 Zanzibari children reported associations between ID and IDA and poor motor ability in infancy $[29,30]$. Additionally, children in our study cohort were generally healthy as indicated by the few children with severe anaemia at five years. A few randomized controlled trials in African children have yielded conflicting findings with some showing significant associations between iron supplementation and developmental scores [44, 45] while others did not find an effect [46, 47]. Of the studies that reported beneficial effects, one included mostly anaemic children and the other reported benefits in anaemic compared to non-anaemic children. Improvement of iron deficiency anaemia related symptoms such as withdrawal and lethargy following iron supplementation may result in improved developmental scores.

Despite mixed findings from epidemiological studies, animal and in vitro studies indicate that iron is important for brain development and normal growth, and its deprivation can result in brain dysfunction manifested in poor performance in developmental assessments [48-50]. Iron plays an important role in neurotransmission and myelination in parts of the brain including the hippocampus and the basal ganglia that are important for memory, learning processes, language and motor function $[9,35,36,51,52]$. Animal studies show that CNS iron decreases before restriction in red cell production occurs [50], and behavioural and cognitive function have been observed to improve with iron-replacement therapy, in many instances before an increase in $\mathrm{Hb}$ concentration implying that the effects of ID may manifest before IDA manifests [50, 53]. However, the application of evidence from animal and in vitro studies to humans may be limited as these studies are conducted in controlled environments with limited confounders and can manipulate iron availability to extents that may not be observed in humans.

A strength of our study is the large sample size and use of both longitudinal and cross-sectional approaches to comprehensively evaluate the effects of maternal and child $\mathrm{Hb}$ levels and anaemia on developmental scores in children. Different developmental domains were assessed at two time-points using a well-validated extensive battery of measures that were specifically adapted to Ugandan children. Also, data on a wide range of potential confounders were available to adjust for in the multivariable analyses. Our study had some limitations. Our study may not be fully representative of Ugandan children since mothers with severe anaemia were excluded from the original trial and all mothers received iron and folate during antenatal care. We also included only about $40 \%$ of participants from the original EMaBS birth cohort in our analyses as developmental scores were assessed in smaller subsets of children. However, our study was adequately powered to detect the reported effect estimates. The long interval between iron measurement at two years and scores at five years may have underestimated the true effects of iron (and ID) on developmental scores. 
Anaemia has multiple aetiologies, and we were unable to ascertain whether the observed effects of anaemia on developmental scores at 15 months were attributable to anaemia generally or to specific causes of anaemia such as ID because iron status was only assessed at two years. Future studies employing measurement of anaemia and iron status and developmental scores together at several time points are recommended.

\section{Conclusions}

Anaemia and ID were highly prevalent in our study. We report that low Hb levels during pregnancy and infancy are associated with reduced psychomotor and language scores in Ugandan children at 15 months. These findings emphasize the need to control for anaemia in pregnant mothers and young children living in Sub-Saharan Africa where children are exposed to different risk factors such as infections and malnutrition. The current study contributes more evidence to the effects of anaemia on early childhood development in SubSaharan Africa where such evidence is still scanty and not conclusive. Further well-conducted randomised controlled trials of iron supplementation are required to evaluate the causal effects of iron status on neurobehavioural outcomes in young children living in Sub-Saharan Africa where anaemia and ID are common.

Author Contributions: M.N., A.M.M., S.H.A., A.A., E.L.W., and A.M.E. conceptualized the study and obtained the relevant data transfer authorization. A.M.E., E.L.W. and M.N. provided the datasets. M.N., A.M.M. and E.L.W. conducted the formal analysis. M.N. and A.A. validated the combination of developmental scores using principal components analyses. M.N., A.M.M and S.H.A. wrote the first draft and M.N. A.M.M., S.H.A., J.M.M, A.A., E.L.W., and A.M.E. reviewed and edited successive drafts of the paper and approved the final version. All authors have read and agreed to the published version of the manuscript.

Funding: This work was funded by Wellcome Trust [Grant numbers 209640 to A.M.M., 110255 to S.H.A., 064693, 079110, 095778 to AME] and with core awards to the KEMRI-Wellcome Trust Research Programme (203077) and by the Medical Research Council [Grant number MR/M025454/1 to AA]. For the purpose of Open Access, the authors have applied a CC-BY public copyright license to any author accepted manuscript version arising from this submission. The funders had no role in the design and conduct of the study, manuscript preparation or interpretation of the findings.

Institutional Review Board Statement: The study was conducted in accordance with the Declaration of Helsinki, and approved by the Medical Research Council (MRC)/ Uganda Virus Research Institute Re-search Ethics Committee (reference numbers: GC/127 and GC/127/15/04/35), Uganda National Council for Science and Technology and the London School of Hygiene and Tropical Medicine Ethics Committee (reference number: 790).

Informed Consent Statement: Informed consent was obtained from all subjects involved in the study.

Data Availability Statement: The data presented in this study are available on request from the Principal Investigator of the EMaBS study (A.M.E). The data are not publicly available due to data privacy restrictions.

Acknowledgments: We thank the participants of the EMaBS study for their voluntary participation, and the EMaBS research team for the data collection.

Conflicts of Interest: The authors declare no conflict of interest. 


\section{References}

1. McCoy, D.C.; Peet, E.D.; Ezzati, M.; Danaei, G.; Black, M.M.; Sudfeld, C.R.; Fawzi, W.; Fink, G. Early childhood developmental status in low-and middle-income countries: national, regional, and global prevalence estimates using predictive modeling. PLoS Med. 2016, 13, e1002034.

2. $\quad$ Black, M.M.; Walker, S.P.; Fernald, L.C.; Andersen, C.T.; DiGirolamo, A.M.; Lu, C.; McCoy, D.C.; Fink, G.; Shawar, Y.R.; Shiffman, J. Early childhood development coming of age: science through the life course. The Lancet. 2017, 389, 77-90.

3. Kassebaum, N.J.; Jasrasaria, R.; Naghavi, M.; Wulf, S.K.; Johns, N.; Lozano, R.; Regan, M.; Weatherall, D.; Chou, D.P.; Eisele, T.P. A systematic analysis of global anemia burden from 1990 to 2010. Am. J. Hematol. 2014, 123, 615-624.

4. Petry, N.; Olofin, I.; Hurrell, R.F.; Boy, E.; Wirth, J.P.; Moursi, M.; Donahue Angel, M.; Rohner, F. The proportion of anemia associated with iron deficiency in low, medium, and high human development index countries: a systematic analysis of national surveys. Nutrients. 2016, 8, 693.

5. Muriuki, J.M.; Mentzer, A.J.; Webb, E.L.; Morovat, A.; Kimita, W.; Ndungu, F.M.; Macharia, A.W.; Crane, R.J.; Berkley, J.A.; Lule, S.A. Estimating the burden of iron deficiency among African children. BMC Med. 2020, 18, 1-14.

6. Stevens, G.A.; Finucane, M.M.; De-Regil, L.M.; Paciorek, C.J.; Flaxman, S.R.; Branca, F.; PeñaRosas, J.P.; Bhutta, Z.A.; Ezzati, M.; Group, N.I.M.S. Global, regional, and national trends in haemoglobin concentration and prevalence of total and severe anaemia in children and pregnant and non-pregnant women for 1995-2011: a systematic analysis of population-representative data. The Lancet Glob. Health. 2013, 1, e16-e25.

7. WHO. The global prevalence of anaemia in 2011; World Health Organization: Geneva, Switzerland, 2015; pp. 43

8. Puig, S.; Ramos-Alonso, L.; Romero, A.M.; Martínez-Pastor, M.T. The elemental role of iron in DNA synthesis and repair. Metallomics. 2017, 9, 1483-1500.

9. Todorich, B.; Pasquini, J.M.; Garcia, C.I.; Paez, P.M.; Connor, J.R. Oligodendrocytes and myelination: the role of iron. Glia. 2009, 57, 467-478.

10. Youdim, M.; Green, A. Iron deficiency and neurotransmitter synthesis and function. Proc. Nutr. Soc. 1978, 37, 173-179.

11. Beard, J.L.; Felt, B.; Schallert, T.; Burhans, M.; Connor, J.R.; Georgieff, M.K. Moderate iron deficiency in infancy: biology and behavior in young rats. Behav. Brain Res. 2006, 170, 224-232.

12. Breton, A.B.; Fox, J.A.; Brownson, M.P.; McEchron, M.D. Postnatal nutritional iron deficiency impairs dopaminergic-mediated synaptic plasticity in the CA1 area of the hippocampus. Nutr. Neurosci. 2015, 18, 241-247.

13. Radlowski, E.C.; Johnson, R.W. Perinatal iron deficiency and neurocognitive development. Front. Hum. Neurosci. 2013, 7, 585.

14. Prado, E.L.; Abbeddou, S.; Adu-Afarwuah, S.; Arimond, M.; Ashorn, P.; Ashorn, U.; Bendabenda, J.; Brown, K.H.; Hess, S.Y.; Kortekangas, E. Predictors and pathways of language and motor development in four prospective cohorts of young children in Ghana, Malawi, and Burkina Faso. $J$. Child. Psychol. Psychiatry. 2017, 58, 1264-1275. 
15. Mireku, M.O.; Davidson, L.L.; Koura, G.K.; Ouédraogo, S.; Boivin, M.J.; Xiong, X.; Accrombessi, M.M.; Massougbodji, A.; Cot, M.; Bodeau-Livinec, F. Prenatal hemoglobin levels and early cognitive and motor functions of one-year-old children. Pediatrics. 2015, 136, e76-e83.

16. Mireku, M.O.; Davidson, L.L.; Boivin, M.J.; Zoumenou, R.; Massougbodji, A.; Cot, M.; BodeauLivinec, F. Prenatal iron deficiency, neonatal ferritin, and infant cognitive function. Pediatrics. 2016, 138.

17. Webb, E.L.; Mawa, P.A.; Ndibazza, J.; Kizito, D.; Namatovu, A.; Kyosiimire-Lugemwa, J.; Nanteza, B.; Nampijja, M.; Muhangi, L.; Woodburn, P.W. Effect of single-dose anthelmintic treatment during pregnancy on an infant's response to immunisation and on susceptibility to infectious diseases in infancy: a randomised, double-blind, placebo-controlled trial. The Lancet. 2011, 377, 52-62.

18. WHO. Serum ferritin concentrations for the assessment of iron status and iron deficiency in populations; World Health Organization: Geneva, Switzerland, 2011.

19. WHO. Guideline on use of ferritin concentrations to assess iron status in populations; World Health Organization: Geneva, Switzerland, 2020.

20. WHO. Haemoglobin concentrations for the diagnosis of anaemia and assessment of severity; World Health Organization: Geneva, Switzerland, 2011.

21. WHO Multicentre Growth Reference Study Group; de Onis, M. WHO Child Growth Standards based on length/height, weight and age. Acta Paediatr. 2006, 95, 76-85.

22. Abubakar, A.; Holding, P.; Van de Vijver, F.; Bomu, G.; Van Baar, A. Developmental monitoring using caregiver reports in a resource-limited setting: the case of Kilifi, Kenya. Acta Paediatr. 2010, 99, 291-297.

23. Abubakar, A.; Holding, P.; Van Baar, A.; Newton, C.; van de Vijver, F.J. Monitoring psychomotor development in a resourcelimited setting: an evaluation of the Kilifi Developmental Inventory. Ann. Trop. Paediatr. 2008, 28, 217-226.

24. Nampijja, M.; Apule, B.; Lule, S.; Akurut, H.; Muhangi, L.; Webb, E.L.; Lewis, C.; Elliott, A.M.; Alcock, K.J. Effects of maternal worm infections and anthelminthic treatment during pregnancy on infant motor and neurocognitive functioning. J. Int. Neuropsychol. Soc. 2012, 18, 1019-1030.

25. Nampijja, M.; Apule, B.; Lule, S.; Akurut, H.; Muhangi, L.; Elliott, A.; Alcock, K.J. Adaptation of Western measures of cognition for assessing 5-year-old semi-urban Ugandan children. Br. J. Educ. Psychol. 2010, 80, 15-30.

26. Namaste, S.M.; Rohner, F.; Huang, J.; Bhushan, N.L.; Flores-Ayala, R.; Kupka, R.; Mei, Z.; Rawat, R.; Williams, A.M.; Raiten, D.J. Adjusting ferritin concentrations for inflammation: Biomarkers Reflecting Inflammation and Nutritional Determinants of Anemia (BRINDA) project. Am. J. Clin. Nutr. 2017, 106, 359S-371S.

27. Nampijja, M.; Kizindo, R.; Apule, B.; Lule, S.; Muhangi, L.; Titman, A.; Elliott, A.; Alcock, K.; Lewis, C. The role of the home environment in neurocognitive development of children living in extreme poverty and with frequent illnesses: a cross-sectional study. Wellcome Open Res. 2018, 3.

28. Bremner, J.G.; Wachs, T.D. The Wiley-Blackwell Handbook of Infant Development, Volume 2: Applied and Policy Issues; Blackwell Publishers Limited: West Sussex, UK., 2010; pp. 14-27.

29. Kariger, P.K.; Stoltzfus, R.J.; Olney, D.; Sazawal, S.; Black, R.; Tielsch, J.M.; Frongillo, E.A.; Khalfan, S.S.; Pollitt, E. Iron deficiency and physical growth predict attainment of walking but not crawling in poorly nourished Zanzibari infants. J. Nutr. 2005, 135, 814-819. 
30. Olney, D.K.; Pollitt, E.; Kariger, P.K.; Khalfan, S.S.; Ali, N.S.; Tielsch, J.M.; Sazawal, S.; Black, R.; Mast, D.; Allen, L.H. Young Zanzibari children with iron deficiency, iron deficiency anemia, stunting, or malaria have lower motor activity scores and spend less time in locomotion. J. Nutr. 2007, 137, 2756-2762.

31. Madanijah, S.; SUkANDAR, D.; Fitri, Y.; Ahmad, A. Assessment of Anemia Status on Physical Development Skills of Children Under Two Years Old in Aceh, Indonesia. J. Nutr. Sci. Vitaminol. . 2020, 66, S463-S467.

32. Rothman, M.; Faber, M.; Covic, N.; Matsungo, T.M.; Cockeran, M.; Kvalsvig, J.D.; Smuts, C.M. Infant development at the age of 6 months in relation to feeding practices, Iron status, and growth in a peri-urban community of South Africa. Nutrients. 2018, 10, 73.

33. Cusick, S.E.; Georgieff, M.K. The Role of Nutrition in Brain Development: The Golden Opportunity of the "First 1000 Days". J Pediatr. 2016, 175, 16-21.

34. Youssef, M.A.; Hassan, E.S.; Yasien, D.G. Effect of iron deficiency anemia on language development in preschool Egyptian children. Int. J. Pediatr. Otorhinolaryngol. 2020, 135, 110114.

35. Bastian, T.W.; von Hohenberg, W.C.; Mickelson, D.J.; Lanier, L.M.; Georgieff, M.K. Iron deficiency impairs developing hippocampal neuron gene expression, energy metabolism, and dendrite complexity. Dev. Neurosci. 2016, 38, 264-276.

36. Carlson, E.S.; Tkac, I.; Magid, R.; O'Connor, M.B.; Andrews, N.C.; Schallert, T.; Gunshin, H.; Georgieff, M.K.; Petryk, A. Iron is essential for neuron development and memory function in mouse hippocampus. J. Nutr. 2009, 139, 672-679.

37. Krebs, N.F.; Lozoff, B.; Georgieff, M.K. Neurodevelopment: the impact of nutrition and inflammation during infancy in low-resource settings. Pediatrics. 2017, 139, S50-S58.

38. Chen, K.; Liu, C.; Liu, X.; Wang, Z.; Luo, R.; Li, S.; Yu, Y.; Alderman, H. Nutrition, Cognition, and Social Emotion among Preschoolers in Poor, Rural Areas of South Central China: Status and Correlates. Nutrients. 2021, 13, 1322.

39. Paxson, C.; Schady, N. Cognitive development among young children in Ecuador the roles of wealth, health, and parenting. J. Hum. Resour. 2007, 42, 49-84.

40. Gashu, D.; Stoecker, B.J.; Bougma, K.; Adish, A.; Haki, G.D.; Marquis, G.S. Stunting, selenium deficiency and anemia are associated with poor cognitive performance in preschool children from rural Ethiopia. Nutr. J. 2015, 15, 1-8.

41. Thorisdottir, A.V.; Gunnarsdottir, I.; Palsson, G.I.; Gretarsson, S.J.; Thorsdottir, I. Iron status and developmental scores in 6-year-olds highlights ongoing need to tackle iron deficiency in infants. Acta Paediatr. 2013, 102, 914-919.

42. Lozoff, B.; Jimenez, E.; Wolf, A.W. Long-term developmental outcome of infants with iron deficiency. N. Engl. J. Med. 1991, 325, 687-694.

43. Pala, E.; Erguven, M.; Guven, S.; Erdogan, M.; Balta, T. Psychomotor development in children with iron deficiency and iron-deficiency anemia. Food. Nutr. Bull. 2010, 31, 431-435.

44. Baumgartner, J.; Smuts, C.M.; Malan, L.; Kvalsvig, J.; van Stuijvenberg, M.E.; Hurrell, R.F.; Zimmermann, M.B. Effects of iron and n-3 fatty acid supplementation, alone and in combination, on cognition in school children: a randomized, double-blind, placebo-controlled intervention in South Africa. Am. J. Clin. Nutr. 2012, 96, 1327-1338.

45. Stoltzfus, R.J.; Kvalsvig, J.D.; Chwaya, H.M.; Montresor, A.; Albonico, M.; Tielsch, J.M.; Savioli, L.; Pollitt, E. Effects of iron supplementation and anthelmintic treatment on motor and language 
medRxiv preprint doi: https://doi.org/10.1101/2022.03.02.22271741; this version posted March 3, 2022. The copyright holder for this preprint (which was not certified by peer review) is the author/funder, who has granted medRxiv a license to display the preprint in perpetuity.

It is made available under a CC-BY 4.0 International license.

development of preschool children in Zanzibar: double blind, placebo controlled study. Br. Med. J. . 2001, 323, 1389.

46. Boivin, M.J.; Giordani, B. Improvements in cognitive performance for schoolchildren in Zaire, Africa, following an iron supplement and treatment for intestinal parasites. J. Pediatr. Psychol. 1993, 18, 249264.

47. Bouhouch, R.R.; El-Fadeli, S.; Andersson, M.; Aboussad, A.; Chabaa, L.; Zeder, C.; Kippler, M.; Baumgartner, J.; Sedki, A.; Zimmermann, M.B. Effects of wheat-flour biscuits fortified with iron and EDTA, alone and in combination, on blood lead concentration, iron status, and cognition in children: a double-blind randomized controlled trial. Am. J. Clin. Nutr. 2016, 104, 1318-1326.

48. Beard, J.L.; Wiesinger, J.A.; Connor, J.R. Pre-and postweaning iron deficiency alters myelination in Sprague-Dawley rats. Dev. Neurosci. 2003, 25, 308-315.

49. Ortiz, E.; Pasquini, J.; Thompson, K.; Felt, B.; Butkus, G.; Beard, J.; Connor, J.R. Effect of manipulation of iron storage, transport, or availability on myelin composition and brain iron content in three different animal models. J. Neurosci. Res. 2004, 77, 681-689.

50. Yehuda, S.; Youdim, M.B. Brain iron: a lesson from animal models. Am. J. Clin. Nutr. 1989, 50, 618629.

51. Beard, J.L. Why iron deficiency is important in infant development. J. Nutr. 2008, 138, 2534-2536.

52. Beard, J.L.; Connor, J.R. Iron status and neural functioning. Annu. Rev. Nutr. 2003, 23, 41-58.

53. Dallman, P.R. Biochemical basis for the manifestations of iron deficiency. Annu. Rev. Nutr. 1986, 6, $13-40$. 